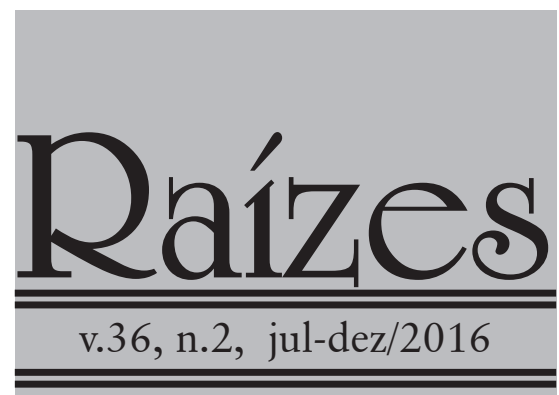

\title{
COMPRAS GOVERNAMENTAIS DE PRODUTOS DA AGRICULTURA FAMILIAR PARA A MERENDA ESCOLAR NO TERRITÓRIO RURAL DO SERIDÓ PARAIBANO ${ }^{1}$
}

\author{
Márcio Caniello, Nina Toralles Caniello, Wendell José de Lima Melo
}

\section{RESUMO}

No escopo da estratégia nacional de desenvolvimento baseada no combate à fome e à pobreza, em que a agricultura familiar figura como setor primordial, o governo do presidente Lula da Silva (2003-2010) implantou várias políticas públicas inovadoras, como o Programa Nacional de Desenvolvimento Sustentável dos Territórios Rurais (PRONAT), voltado para o fortalecimento da agricultura familiar por meio de fóruns deliberativos participativos, e inovou políticas públicas antigas, como o Programa Nacional de Alimentação Escolar (PNAE), exigindo que pelo menos 30\% do valor repassado pela União aos entes federativos para a aquisição de alimentos para a merenda escolar deva ser utilizado na compra de gêneros provenientes da agricultura familiar. Este trabalho visa analisar o desempenho das compras governamentais para a merenda escolar nos municípios do Território Rural do Seridó Paraibano entre 2010 e 2014, de maneira a confrontar os constrangimentos ambientais, culturais, institucionais, organizacionais e políticos diagnosticados por pesquisa-ação realizada no território com o potencial produtivo e organizativo da agricultura familiar no quadro do Fórum Territorial.

Palavras-chave: Desenvolvimento territorial; Políticas públicas; Combate à fome e à pobreza.

\section{PUBLIC PROCUREMENT OF SMALLHOLDER FARMING PRODUCTS FOR SCHOOL MEALS IN THE RURAL TERRITORY OF SERIDÓ IN PARAÍBA, BRAZIL}

\section{ABSTRACT}

In the scope of the national sustainable development strategy based on the fight against hunger and poverty, where smallholder farming constitutes a key sector, the government of former President Lula da Silva (2003-2010) implemented several innovative public policies, such as the National Program for Sustainable Development of Rural Territories (PRONAT), aimed at strengthening smallholder farming by means of participatory deliberative forums. Besides, it innovated old public policies such as the National School Feeding Programme (PNAE), requiring that at least $30 \%$ of the amount transferred by the Union to municipalities and states for school meals must be used in the purchase of genres from smallholder farmers. This paper aims to analyse the performance of government procurement of smallholder farming products in the Rural Territory of Seridó in the state of Paraiba between the years 2010-2014, confronting environmental, cultural, institutional, organizational and political constraints with the productive and organizational potential of smallholder farming.

Key words: Territorial Development; Public policy; Fighting hunger and poverty.

Doutor em Sociologia, Professor Associado da Universidade Federal de Campina Grande (UFCG), Programa de Pós-Graduação em Ciências Sociais (PPGCS), coordenador do Núcleo de Extensão Multiterritorial do Agreste Paraibano (NEXTAP), e-mail:marciocaniello@gmail.com.

Médica Veterinária, Bolsista da Universidade Federal de Campina Grande (UFCG)/CNPq, Núcleo de Extensão Multiterritorial do Agreste Paraibano (NEXTAP), e-mail: ninatoralles@hotmail.com.

Mestre em Engenharia Agrícola, Bolsista da Universidade Federal de Campina Grande (UFCG)/CNPq, Núcleo de Extensão Multiterritorial do Agreste Paraibano (NEXTAP), e-mail: wendell.zootec@gmail.com.

1 Trabalho realizado nos quadros do Projeto de Pesquisa e Extensão "Acompanhamento, Assessoramento e Monitoramento das Instâncias de Gestão Social dos Territórios da Borborema, Curimataú e Seridó Paraibano (Paraíba)”, aprovado na Chamada Pública CNPq/MDA/SPM-PR nº 011/2014. Este artigo é uma versão ampliada e atualizada do trabalho. 
Uma das principais dificuldades para a manutenção e reprodução da unidade familiar camponesa é a comercialização de sua produção, pois, como produtores "periféricos" (FOSTER, 1967, p. 6) e descapitalizados, que mantêm um parco controle sobre os meios de produção (WOLF, 1970, p. 16), os camponeses $^{2}$ são "particularmente mal equipados" (MAZOYER; ROUDART, 2010, p. 27) e estão situados num "contexto caracterizado por relações de dependência, marginalização e privações” (PLOEG, 2008, p. 40). Por isso, esse grupo social sofre um duplo bloqueio: por um lado, sua agricultura ${ }^{3}$ apresenta uma produtividade baixa em relação às agriculturas empresarial e capitalista ${ }^{4}$, o que a torna pouco competitiva economicamente frente a estas (MAZOYER; ROUDART, 2010, p. 499) e, por outro lado, o escoamento da produção encontrase fortemente premido pela escassez de capital de giro e de conhecimento sobre o mercado por parte dos produtores ${ }^{5}$, por estruturas precárias de armazenamento e processamento, pela dificuldade quanto ao cumprimento de regras de classificação, acondicionamento, de higiene e sanitárias inerentes à comercialização de alimentos e, finalmente, por obstáculos quanto à logística e ao próprio acesso aos mercados. Daí, a condição histórica de penúria que caracteriza o campesinato, sobretudo nos países em desenvolvimento (MAZOYER; ROUDART, 2010, p. 47).

Sem negligenciar os mercados locais e feiras onde tradicionalmente a produção camponesa é comercializada, bem como o avan- ço das produções orgânica e agroecológica que conferem uma maior competitividade aos produtos da agricultura camponesa no mercado em geral vis-à-vis sua qualidade e sanidade, recentemente as compras governamentais vêm se firmando como uma política pública importante em nível mundial, pois articulam o estímulo à agricultura familiar e a segurança alimentar de beneficiários de programas institucionais, seja em países desenvolvidos (SONNINO, 2009), seja no âmbito das estratégias de desenvolvimento rural e de combate à fome e à miséria nos países em desenvolvimento (FAO, 2013), inclusive no Brasil (FORNAZIER e BELIK, 2013, p. 214; CONCEIÇÃO, 2015, p. 140; GRISA e PORTO, 2015; TRICHES, 2015; BELIK e CUNHA, 2015, p. 228; FAO, 2016, p. 119ss).

Nesse sentido, o governo brasileiro criou o Programa de Aquisição de Alimentos (PAA) em 2003 e inovou o Programa Nacional de Alimentação Escolar (PNAE) por meio da Lei $\mathrm{n}^{\circ}$ 11.947, de 16 de junho de 2009, que determina que no mínimo 30\% do valor repassado a estados, municípios e Distrito Federal pelo Fundo Nacional de Desenvolvimento da Educação (FNDE) para a merenda escolar deve ser utilizado na compra de gêneros alimentícios da agricultura familiar. Estes dois programas fazem parte da "terceira geração de políticas para a agricultura familiar" (GRISA e SCHNEIDER, 2015: 36-42) instituída pelos governos Lula e Dilma Rousseff, nos quadros da estratégia de combate à fome, redução da pobreza e redistribuição de ren-

2 Sem entrarmos nos meandros de uma discussão teórica e conceitual que julgamos desnecessária, neste artigo utilizamos os termos "camponês" ou "camponesa" como vocábulos correspondentes a "agricultor ou agricultora familiar" e vice-versa.

3 Aqui seguimos a definição de PLOEG (2008, p. 17): "A agricultura camponesa se baseia fundamentalmente no uso sustentado do capital ecológico, sendo orientada para a defesa e melhoramento das condições de vida dos camponeses. Uma das principais características desse tipo de agricultura é, muitas vezes, a multifuncionalidade, sendo a mão-de-obra fundamentalmente familiar (ou mobilizada dentro da comunidade rural através de relações de reciprocidade) e pertencendo as terras e outros meios de produção essenciais também à família. A produção é orientada para o mercado, mas também para a reprodução da unidade agrícola e da família”.

4 De acordo com PLOEG (2008, p. 17-18), a “agricultura do tipo empresarial” é essencialmente baseada em capital financeiro e industrial (sob a forma de crédito, insumos industriais e tecnologias), sua expansão se realiza pelo aumento em escala e os produtores são ativamente dependentes dos mercados (especialmente de mercados de insumos), enquanto a "agricultura capitalista ou corporativa de grande escala" é feita "sob a égide do modelo agroexportador" e engloba uma rede bastante extensa de empresas agrícolas de grande mobilidade, que utiliza mão-de-obra quase exclusivamente baseada em trabalhadores assalariados e cuja produção é voltada para a maximização do lucro e vista como função desta.

5 "A comercialização de modo geral necessita de um grande volume de capital de curtíssimo prazo e envolve riscos atinentes às flutuações da demanda e dos preços de mercado" (BELIK; CUNHA, 215, p. 219). 
da em que, como demonstramos alhures, a agricultura familiar figura como protagonista (CANIELLO, 2016).

Também fez parte dessa estratégia o PRONAT - Programa Nacional de Desenvolvimento Sustentável dos Territórios Rurais, referencial para a construção de um "Brasil rural com gente" (DELGADO e LEITE, 2015, p. 253), cujo enfoque tinha como base a integração dessas políticas, visando superar o "setorialismo" que historicamente as caracterizaram, ampliar seu escopo e aprofundar o caráter participativo e decisório dos agricultores familiares em seu planejamento, aplicação, gestão e monitoramento (Brasil, 2003 e 2008).

Em linhas gerais, o PRONAT estabeleceu a delimitação de territórios rurais envolvendo conjuntos de municípios agrupados por características geográficas, sociais, econômicas e identitárias comuns e a constituição, em cada qual, de uma instância deliberativa, denominada colegiado ou fórum, formada paritariamente por representantes da sociedade civil (associações, sindicatos, ONGs, cooperativas, etc.) e dos governos federal, estadual e municipal ${ }^{6}$. É nesses dispositivos de governança territorial que se efetiva o chamado "ciclo de gestão social”, isto é, o processo participativo de debate, disputas e concertação sobre o planejamento, implementação, avaliação e monitoramento de políticas públicas voltadas para o desenvolvimento rural.

Em 2014, o governo federal orientou os colegiados territoriais - a partir de então assessorados pelos Núcleos de Extensão em Desenvolvimento Territorial (NEDETs) ${ }^{7}-\mathrm{a}$ acompanharem a execução dos recursos des- centralizados pelo PNAE para a merenda escolar, particularmente a parcela destinada à compra dos produtos da agricultura familiar. Este trabalho relata o processo de pesquisa-ação sobre compras governamentais para a merenda escolar nos municípios do Território do Seridó Paraibano realizada pelo NEDET Seridó/UFCG em parceria com o Fórum de Desenvolvimento Territorial Sustentável do Seridó Paraibano no ano de 2015. Temos por objetivo relatar este processo e refletir sobre as principais dificuldades apontadas pelos atores territoriais para a efetivação da compra direta de gêneros alimentícios da agricultura familiar para a merenda escolar no território, bem como as perspectivas para sua consecução.

\section{O PROGRAMA NACIONAL DE ALIMEN- TAÇÃO ESCOLAR}

O Programa Nacional de Alimentação Escolar (PNAE), cujas origens remontam aos anos 1940, é gerenciado pelo Fundo Nacional de Desenvolvimento da Educação (FNDE) e visa à transferência, em caráter suplementar, de recursos financeiros aos estados, ao Distrito Federal e aos municípios, destinados a suprir, parcialmente, as necessidades nutricionais dos alunos. É considerado um dos maiores programas na área de alimentação escolar no mundo e é o único com atendimento universalizado. Em 2014, foram atendidos aproximadamente 42,2 milhões de alunos com um investimento de cerca de R \$ 3,6 bilhões ${ }^{8}$.

Desde sua criação até 1993, a execução do programa era centralizada, pois o Ministério da Educação planejava os cardápios,

6 Para a instituição dos territórios e de seus respectivos colegiados há normas e orientações emanadas da SDT e do Conselho Nacional de Desenvolvimento Rural Sustentável (Condraf), que é a instância que homologa os territórios oficialmente.

7 De maneira a viabilizar o funcionamento dos colegiados territoriais e encaminhar os processos e produtos demandados pelo PRONAT, a Secretaria de Desenvolvimento Territorial (SDT) do Ministério do Desenvolvimento Agrário (MDA), gestora do Programa, instituiu a chamada "assessoria territorial", baseada numa rede de articuladores e colaboradores contratados, oriundos de ONGs ou de serviços de assessoria. Embora tenha produzido avanços importantes para a consolidação da estratégia de desenvolvimento territorial, esse modelo apresentou muitos problemas associados a dificuldades legais quanto ao financiamento da atividade, o que redundou numa grande instabilidade, rotatividade e até mesmo ausência de assessores nos territórios (PIRAUX e CANIELLO, 2015). Por esta razão, em 2013 a SDT resolveu mudar a estrutura da assessoria territorial, que passou a ser executada pelos NEDETs, por meio de parcerias com Universidades e Institutos Tecnológicos públicos, mediadas pelo CNPq. Em outro trabalho analisamos este processo de assessoria territorial (TEIXEIRA e CANIELLO, 2016).

8http://www.fnde.gov.br/programas/alimentacao-escolar/alimentacao-escolar-consultas/alimentacao-escolar-dados-estatisticos, acesso em 24/08/2016. 
adquiria os gêneros, fazia seu controle de qualidade e se responsabilizava pela distribuição dos alimentos em todo o território nacional. Em 1994, foi instituída a descentralização dos recursos para execução do Programa mediante celebração de convênios entre o Governo Federal e os entes federados e, a partir de 1998, a transferência de recursos passou a ser feita automaticamente, sem a necessidade de celebração de convênios ou quaisquer outros instrumentos similares, permitindo maior agilidade ao processo.

Além da descentralização, dois avanços importantes se efetivaram no início dos anos 2000. Primeiramente, a obrigatoriedade de que $70 \%$ dos recursos transferidos pelo governo federal fossem aplicados exclusivamente em produtos básicos e o respeito aos hábitos alimentares regionais e à vocação agrícola do município. Outro avanço foi a instituição, em cada município brasileiro, do Conselho de Alimentação Escolar (CAE) como órgão deliberativo, fiscalizador e de assessoramento para a execução do Programa. Atualmente, os CAEs são formados por representantes de entidades civis organizadas, dos trabalhadores da educação, dos discentes, dos pais de alunos e representantes do poder Executivo.

Como citado anteriormente, em 2009 foi promulgada a Lei 11.947, que dispõe sobre o atendimento da alimentação escolar e do Programa Dinheiro Direto na Escola aos alunos da educação básica, que estabelece a exigência de que, no mínimo, 30\% dos repasses do FNDE sejam investidos na aquisição de produtos da agricultura familiar. O processo envolve dez passos, que são monitorados, fiscalizados e passíveis de aprovação pelo Conselho de Alimentação Escolar (CAE).

O primeiro é o conhecimento dos recursos disponíveis. As Entidades Executoras
(EEx), isto é, escolas e secretarias de Educação, consultam o FNDE sobre os recursos disponíveis, cujo montante é calculado com base no censo escolar do ano anterior. Em seguida, a produção é mapeada para identificar os produtos disponíveis na região, a quantidade e a sazonalidade 9 . Com o mapeamento realizado e o conhecimento dos produtos que podem ser fornecidos na região, o nutricionista da EEx, responsável técnico do PNAE, elabora o cardápio para alimentação dos alunos, conforme as exigências nutricionais preconizadas. Conhecidos os produtos e as quantidades a serem adquiridas, o passo seguinte é a definição dos preços ${ }^{10}$ e elaboração do edital de Chamada Pública, que é um procedimento licitatório bastante simplificado, conforme preconiza a Resolução No 4/2015, do FNDE.

Com o edital publicado, fica aberto o prazo para a elaboração e envio dos projetos de venda, que é de responsabilidade dos agricultores familiares ${ }^{11}$. No dia marcado as propostas serão habilitadas mediante a conformidade da documentação requerida no edital. Em seguida serão classificadas conforme os critérios de seleção, a saber: (1) fornecedores locais do município; (2) assentamentos de reforma agrária, comunidades tradicionais indígenas e comunidades quilombolas; (3) fornecedores de gêneros alimentícios certificados como orgânicos ou agroecológicos; (4) grupos formais, grupos informais e fornecedores individuais, nessa ordem; (5) organizações com maior porcentagem de agricultores familiares e/ou empreendedores familiares no seu quadro de sócios, conforme DAP jurídica.

Após a classificação, é feita a análise da qualidade dos produtos e, em seguida, o compromisso de compra é formalizado entre a EEx e os fornecedores através de um contrato, em acordo com a Lei de Licitações e Contratos ${ }^{12}$. Com o início das entregas dos produtos, é reco-

9 Na Paraíba, é a EMATER que se responsabiliza pelo mapeamento da produção.

10 Para a definição dos preços deve ser realizada uma consulta na região, em no mínimo três estabelecimentos comerciais, podendo ainda serem usados como referências os valores da CONAB para o Programa de Aquisição de Alimentos (PAA).

11 O produtor deverá apresentar a Declaração de Aptidão ao PRONAF-DAP para ser habilitado.

12 Lei 8.666/1903 Regulamenta o art. 37, inciso XXI, da Constituição Federal, institui normas para licitações e contratos da Administração Pública e dá outras providências. 
mendado que o fornecedor assine, junto com o representante da EEx, o "termo de recebimento”. Na ocasião o fornecedor também deverá emitir e entregar o documento fiscal.

As EEx recebem os recursos mensalmente em contas específicas e, desta forma, não há justificativa para que o Poder Público atrase os pagamentos aos fornecedores.

O DESEMPENHO DAS COMPRAS GOVERNAMENTAIS DE PRODUTOS DA AGRICULTURA FAMILIAR NO ÂMBITO DO PNAE

Entre 2011 e 2014, o FNDE repassou cerca de R\$ 13 bilhões para os entes federados empregarem na merenda escolar, sendo que R\$ 1,89 bilhões $(14,5 \%)$ foram efetivamente investidos na aquisição de gêneros fornecidos pelos agricultores familiares e suas organizações ${ }^{13}$. A média percentual dá uma falsa impressão, pois indica que o desempenho do cumprimento da lei aproxima-se da metade do exigido (mínimo de 30\%), mas um olhar mais atento às estatísticas indica que a situação é bem mais grave. De fato, embora o percentual médio venha subindo, passando de 7,8\% em 2011 para 21,4\% em 2014, neste último ano nada menos do que $61 \%$ dos gestores da merenda escolar não cumpriram o percentual mínimo e, das 5.519 EEx, 1.266 (23\%) não realizaram nenhuma compra de gêneros da agricultura familiar para a merenda escolar ${ }^{14}$.

No Estado da Paraíba a situação é ainda mais séria, pois, entre 2011 e 2014, dos 223 munícipios, apenas sete (3\%) atenderam ao mandado da Lei em todos os exercícios fiscais, enquanto 103 (46\%) nunca efetuaram o percentual mínimo de compras. Ademais, a Secretaria Estadual de Educação, que teve um aporte de cerca de R 112 milhões no mesmo período - o que representa 39\% dos repasses federais nesta rubrica para a Paraíba - executou pouco mais de R\$ 4 milhões, isto é, menos de 4\% do total. Assim, em quatro anos de implementação dessa política pública, dos cerca de R\$ 288 milhões repassados pelo Governo Federal para a aquisição de produtos da agricultura familiar para a merenda escolar na $\mathrm{Pa}-$ raíba, as prefeituras e o Governo do Estado executaram apenas $\mathrm{R} \$ 30$ milhões (10,65\%), onerando os pequenos produtores em mais de R\$ 257 milhões.

No Território do Seridó paraibano, o desempenho também é deficitário, embora se perceba o esforço de algumas prefeituras em cumprirem o percentual mínimo de 30\%, conforme se pode observar na Tabela 1 .

Tabela 1 - Percentual de Compras Governamentais da Agricultura Familiar para a MeRENDA Escolar no Território do SERIdó PARAIBANO (2011-2014)

\begin{tabular}{|c|c|c|c|c|}
\hline MunicíPIO / ANO & 2011 & 2012 & 2013 & 2014 \\
\hline Cubati & $37,05 \%$ & $30,82 \%$ & $0,00 \%$ & $18,26 \%$ \\
\hline Pocinhos & $\begin{array}{c}\text { Sem } \\
\text { informações }\end{array}$ & $\begin{array}{c}\text { Sem } \\
\text { informações }\end{array}$ & $42,98 \%$ & $54,18 \%$ \\
\hline Pedra Lavrada & $29,08 \%$ & $23,14 \%$ & $32,22 \%$ & $28,17 \%$ \\
\hline Juazeirinho & $\begin{array}{c}\text { Sem i } \\
\text { nformações }\end{array}$ & $\begin{array}{c}\text { Sem } \\
\text { informações }\end{array}$ & $0,00 \%$ & $0,00 \%$ \\
\hline Olivedos & $29,11 \%$ & $28,62 \%$ & $0,00 \%$ & $25,62 \%$ \\
\hline $\begin{array}{l}\text { São Vicente } \\
\text { do Seridó }\end{array}$ & $19,94 \%$ & $16,35 \%$ & $0,00 \%$ & $0,00 \%$ \\
\hline Tenório & $11,02 \%$ & $0,00 \%$ & $0,00 \%$ & $21,88 \%$ \\
\hline
\end{tabular}

Fonte: Dados do FNDE trabalhados pelos autores

Diante desse baixo desempenho e considerando as compras governamentais como um elemento estratégico para a sustentabilidade da agricultura familiar no Seridó paraibano, o Fórum Territorial, reunido em plenária no dia 11 de fevereiro de 2015, deliberou, por unanimidade, pela realização, por parte do NEDET, de um diagnóstico da situação, com vistas a definir uma agenda para as prefeituras efetivarem a compra mínima de 30\% em produtos da agricultura familiar com recursos do PNAE. Este artigo procura relatar esse processo e suas repercussões.

13 O Portal do FNDE (http://www.fnde.gov.br/programas/alimentacao-escolar/alimentacao-escolar-consultas/dados-da-agricultura-familiar) disponibiliza apenas dados referentes a 2011-2014. Acesso em 24/08/2016, para todas as remissões estatísticas neste trabalho.

14 Segundo dados do Portal do FNDE (ver nota anterior) trabalhados pelos autores. 
PERCURSO METODOLÓGICO: UMA PESQUISA-AÇÃO

Em face da natureza da demanda e das relações entre o NEDET e o Fórum, optamos por adotar a pesquisa-ação como metodologia, uma vez que ela é "um tipo de pesquisa social com base empírica que é concebida e realizada em estreita associação com a resolução de um problema coletivo e no qual os pesquisadores e os participantes representativos da situação ou do problema estão envolvidos de modo cooperativo ou participativo" (THIOLLENT, 1986, p. 14). Neste sentido, adotamos um ciclo de pesquisa, envolvendo as seguintes fases, tal como proposto por TRIPP (2005, p. 446): (i) identificação do problema; (ii) planejamento de soluções; (iii) implementação das soluções; (iv) monitoramento do processo; e (v) avaliação de sua eficácia.

Para a identificação do problema, ou o diagnóstico propriamente dito, optou-se pela realização de "mesas de diálogo" nos sete municípios do território, articuladas pelos assessores do NEDET e membros da Coordenação Executiva do Fórum. As mesas, realizadas no período de 13 de fevereiro a 17 de março de 2015, contaram com a presença de secretários municipais de Agricultura e Educação ou seus representantes, nutricionistas, membros dos Conselhos de Alimentação Escolar (CAE), agricultores familiares através de representantes de seus sindicatos ou organizações, representantes dos Conselhos Municipais de Desenvolvimento Rural Sustentável (CMDRS), técnicos da EMATER local, representantes das escolas públicas e membros do Fórum, num total de 110 participantes nos sete municípios. Em linhas gerais, cada reunião era iniciada com a apresentação, por parte dos assessores do NEDET, do desempenho do município quanto à execução dos recursos destinados pelo FNDE para a aquisição de produ- tos da agricultura. A partir daí, o debate era aberto, focando nas dificuldades enfrentadas, em suas razões e possíveis caminhos de resolução. Ao final das reuniões eram definidos encaminhamentos práticos para os atores envolvidos, visando a resolução dos problemas mais simples diagnosticados ao nível do município.

A segunda fase, de planejamento das soluções, foi iniciada pela sistematização dos dados levantados em cada município, a qual foi apresentada em plenária do Fórum, realizada no dia 18 de março de 2015, quando ficou deliberado que o NEDET apresentaria esta sistematização, correlacionando-a a dados secundários, em reunião da Câmara Temática de Produção e Economia Solidária, que foi realizada em 7 de maio de 2015. As conclusões desta reunião foram apresentadas e discutidas em Plenária Territorial.

A terceira fase, de implementação de soluções, envolveu o encaminhamento de ações definidas pelo Fórum, que apontaremos posteriormente no corpo deste trabalho, e a apresentação dos resultados da pesquisa-ação em evento sobre o tema das compras governamentais no âmbito do PNAE no estado da Paraíba promovido pela Procuradoria Regional dos Direitos do Cidadão (PRDC) e EMATER/ $\mathrm{PB}$, realizado em 13 de outubro de 2015. O principal resultado do evento foi a elaboração de um documento, baseado em Estudo Técnico sobre o desempenho das compras governamentais na Paraíba elaborado pelo NEXTAP/ UFCG $^{15}$, que seria encaminhado pela PRDC, em forma de notificação, a todas as Entidades Executoras do PNAE no Estado (223 prefeituras e a secretaria estadual de Educação), admoestando-as a cumprir o percentual mínimo de compras da agricultura familiar com recursos do PNAE em 2016.

A quarta fase, de monitoramento do processo, foi desenvolvida pelo NEDET/Seridó em parceria com o Núcleo Diretivo do Fórum, por meio de duas ações: uma segun-

15 Núcleo Multiterritorial de Extensão Territorial do Agreste Paraibano, composto pelos NEDETs Borborema, Curimataú e Seridó Paraibano, responsável pela execução do Projeto de Pesquisa e Extensão "Acompanhamento, Assessoramento e Monitoramento das Instâncias de Gestão Social dos Territórios da Borborema, Curimataú e Seridó Paraibano (Paraíba)", aprovado na Chamada Pública CNPq/MDA/SPM-PR nº 011/2014. 
da rodada de mesas de diálogo, realizada no período de 23 de novembro a 16 de dezembro de 2015, e pela discussão do tema nas reuniões plenárias e das câmaras temáticas.

A avaliação, quinta fase do processo, será realizada em reunião plenária especial dedicada exclusivamente ao tema, quando este trabalho será apresentado aos atores territoriais.

\section{O TERRITÓRIO RURAL DO SERIDÓ PARAIBANO}

De maneira a situar o leitor no palco deste trabalho, faremos uma breve apresentação do Território do Seridó Paraibano, situado no Agreste da Paraíba. O Território tem uma extensão de $2.284 \mathrm{Km}^{2}$ (4\% da área do Estado) e é constituído por sete municípios: Cubati, Juazeirinho, Olivedos, Pedra Lavrada, Pocinhos, São Vicente do Seridó e Tenório.

Seu clima é semiárido, com temperaturas elevadas (médias entre $24^{\circ} \mathrm{C}$ e $32^{\circ} \mathrm{C}$ ), luz solar intensa (entre 2.000 e 3.000 horas por ano) e irregularidade de chuvas (médias abaixo de $500 \mathrm{~mm} / \mathrm{ano}$ ), provocando seca em períodos prolongados e chuvas reduzidas, mas às vezes torrenciais, em períodos relativamente curtos. Quanto aos solos, há uma grande predominância de solos rasos e pedregosos (Litolico e Bruno não cálcico), alguns com tendência a salinizar águas superficiais (Solonedz Solodizado) e outros (Regosol) fáceis de serem erodidos pela predominância de textura arenosa, mas também há solos mais profundos em locais com relevos acentuados. Evidentemente, tal configuração ecológica aponta para graves problemas hídricos, agravados pelo fato de que o território é conhecido pela predominância de riachos e lençol freático salobros e salgados.

A população do território é de 64.819 habitantes, sendo 53,62\% urbana e 46,38\% rural (Brasil, 2011). Dos seus 6.270 estabelecimentos rurais, 5.333 (85\%) são da agricultura familiar, os quais concentram $84 \%$ do pessoal ocupado e geram $82 \%$ do valor das receitas do setor que, em 2006, foram estimados em R \$ 40 milhões em valores correntes (Brasil, 2009) ou R\$ 69 milhões em valores atuais.

\section{Gráfico 1 - Perfil Agrário do Território \\ Rural do Seridó Paraibano (\%)}

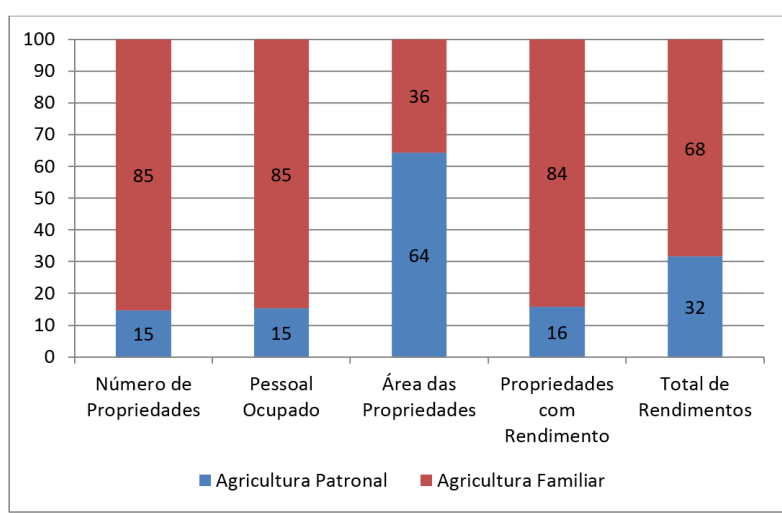

Fonte: elaboração própria com dados do IBGE (Brasil, 2009)

Há 5.920 famílias distribuídas em 168 comunidades rurais no território, entre as quais 122 (73\%) estão formalmente organizadas em associações ou cooperativas, enquanto as restantes mantêm relações de cooperação coletiva informais (Paraíba, 2014). No território destaca-se a atuação, há duas décadas, do Coletivo das Organizações da Agricultura Familiar, vinculado à Articulação do Semiárido (ASA/Brasil), que congrega várias associações e cooperativas, desenvolvendo a estruturação das unidades produtivas familiares e estratégias de comercialização de seus produtos. A Tabela 1 mostra o potencial produtivo das comunidades:

Tabela 2 - Potencial PRodutivo das COMUNidades rurais do Território do Seridó Paraibano

$\begin{array}{ccc}\text { ATIVIDADE } & \text { COMUNIDADES } & \% \\ \text { Caprinovinocultura } & 90 & 54 \% \\ \text { Bovinocultura } & 67 & 40 \% \\ \text { Roçados } & 43 & 26 \% \\ \text { Avicultura } & 27 & 16 \% \\ \text { Fruticultura } & 23 & 14 \% \\ \text { Horticultura } & 19 & 11 \%\end{array}$

Fonte: Paraíba, 2014

Em face do perfil produtivo e organizativo da agricultura familiar no Território do Seridó, a presença da EMATER e de Conselhos de Alimentação Escolar (CAE) em todos os municípios e o ativo funcionamento do Fórum de Desenvolvimento Territorial, era de se esperar que as compras governamentais para 
a merenda escolar respeitassem o mínimo de $30 \%$, mas não é isso que se observa. Veremos, a seguir, quais as causas e razões avocadas pelos atores territoriais para tal fato e as soluções que eles planejaram empreender.

\section{AS AGRURAS DO SEMIÁRIDO E A VONTADE POLÍTICA}

Os representantes governamentais afirmam, em sua imensa maioria, que a maior dificuldade para adquirir produtos da agricultura familiar no Território do Seridó está relacionada às condições ecológicas adversas do Semiárido, fundamentalmente a escassez hídrica, o que dificultaria um fornecimento de gêneros na quantidade e regularidade necessárias para manter a oferta de merenda escolar aos alunos durante todo o ano letivo.

Para os camponeses e suas organizações, isso soa como uma desculpa, pois, para eles, o principal fator de bloqueio dessa política pública no Território é a falta de vontade política dos gestores municipais. Asseguram que têm amplas condições para garantir a qualidade, quantidade e regularidade em suas entregas, fundamentando-se no chamado "projeto político de convivência com o Semiárido" ${ }^{16}$, viabilizado pelo acesso a tecnologias apropriadas, como as de captação e armazenamento da água de chuva, de aproveitamento de águas servidas, de manejo agroecológico, entre outras, aliás estimuladas por um conjunto de programas federais na última década.

Considerando estas duas ideias básicas que predominaram na avaliação dos atores envolvidos, procuramos levantar as séries históricas do IBGE sobre a produção agropecuária e extrativista ${ }^{17}$ e cruzá-las com a média de precipitação pluviométrica da Agência Executiva de Gestão das Águas da Paraíba (AESA), que sumaria o regime de chuvas dos municípios ao longo de 21 anos $^{18}$. Um estudo baseado nestes dados foi apresentado ao debate na Câmara Temática de Produção e Economia Solidária, anteriormente citada. Descrevemos brevemente a discussão.

Primeiramente, o Gráfico 2, que traz a soma da produção das principais lavouras temporárias do Território - mandioca, milho, feijão, batata-doce, tomate, batata-inglesa e fava - parece confirmar a visão dos gestores públicos, pois observa-se uma clara relação entre o volume da produção agrícola e a quantidade de chuvas anuais.

Gráfico 2 - Lavouras Temporárias vs. Média da Precipitação Anual (Território do Seridó PARAIBANO)

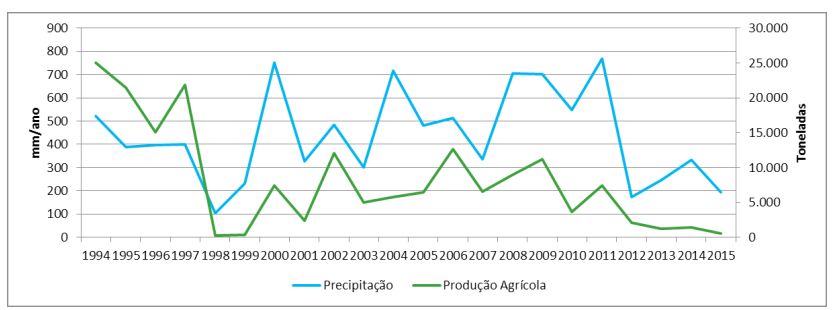

Fonte: elaboração própria com dados do IBGE (PAM) e AESA

De fato, são evidentes os baixíssimos níveis da produção no quadriênio 2012-2015, em que o Nordeste vive a sua maior seca dos últimos 50 anos e o Território apresenta uma média pluviométrica de inacreditáveis 237 mm/ano. Contudo, devemos também observar que mesmo em anos mais recentes com boas chuvas, como no quadriênio 2008-2011 (média de $680 \mathrm{~mm} / \mathrm{ano}$ ), a produção das lavouras temporárias não é tão boa como em anos anteriores. Se naquele quadriênio favorável a média da produção foi de 7.800 toneladas/ano, no quadriênio 1994-1997 (427 $\mathrm{mm} / \mathrm{ano})$, a produção anual atingiu uma média de 20.847 toneladas/ano, quase o triplo. Assim, configura-se uma linha decrescente da produção agrícola da década de 1990 aos dias atuais, o que também se observa em relação 
aos efetivos bovino, caprino, ovino e suíno, mas não ao efetivo de galináceos. Seja como for, resta demonstrado que realmente as culturas temporárias sofrem com a falta de chuvas, mas também que há muitos outros fatores que podem interferir na relação entre a pluviosidade e a produção agrícola.

Com efeito, quando observamos o comportamento da produção de manga (lavoura permanente) e umbu (extrativismo), frutas mais produzidas no Território, essa correlação não incide, como se pode verificar no Gráfico 3, que mostra, inclusive, uma retomada da regularidade da produção entre 2012 e 2015, embora ainda um pouco abaixo da média histórica.

Gráfico 3- Produção de Frutas vs. Média da Precipitação Anual (Território do Seridó PARAibano)

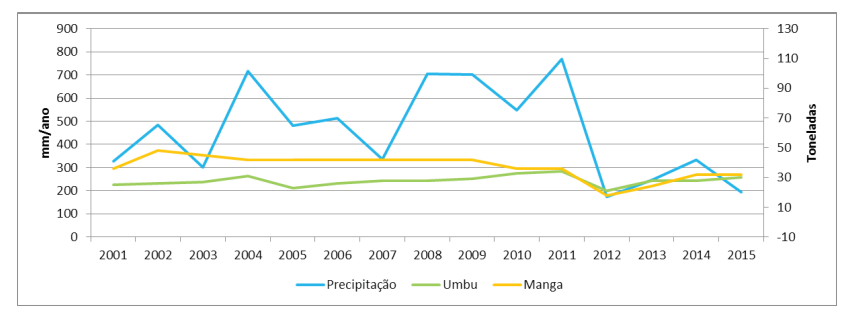

Fonte: elaboração própria com dados do IBGE (PAM e PEVS) e AESA

Mas é o comportamento da produção de leite no Território (Gráfico 4), que parece confirmar a visão dos camponeses e de suas organizações.

Gráfico 4 - Produção de Leite vs. Média da Precipitação Anual (Território do Seridó Paraibano)

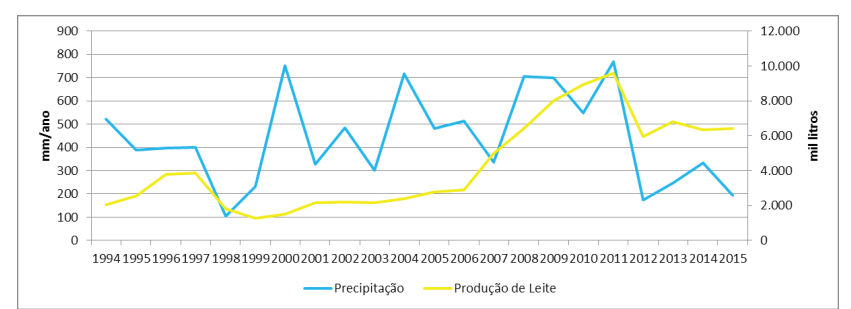

Fonte: elaboração própria com dados do IBGE (PPM) e AESA
Como se pode observar no Gráfico 4, há uma coincidência entre as tendências da produção de leite e da média pluviométrica entre 1994 e 1999, mas a partir do ano 2000 há uma evolução significativa da produção no Território, independentemente das oscilações da precipitação pluviométrica, a não ser a partir de 2012, ano em que choveu menos de $200 \mathrm{~mm}$, um “ponto fora da curva” na média histórica observada, o que provocou a redução do efetivo bovino territorial em 32\%. Evidentemente, uma seca tão pronunciada tem seus impactos, mas observamos no Gráfico que a produção se estabiliza em torno de 6 milhões de litros anuais neste período extraordinariamente seco, bem acima da média histórica (4 milhões e 300 mil litros/ano).

A conclusão dos participantes da reunião da Câmara Temática de Produção e Economia Solidária foi que tal comportamento produtivo pode ser explicado exatamente pela chamada "vontade política", pois a partir do ano 2000, o governo do Estado da Paraíba instituiu o Programa do Leite, sistema de compras governamentais do produto para sua distribuição a famílias carentes. Tal hipótese se fortalece com a evolução ainda mais pronunciada da produção leiteira a partir de 2003, ao que reputam camponeses, suas organizações e técnicos da EMATER e de outras instituições participantes do debate na Câmara Técnica, pela instituição do Programa de Aquisição de Alimentos (PAA), que veio a ampliar significativamente as compras do produto no Território ${ }^{19}$.

Assim, parece óbvio que as agruras edafoclimáticas do Semiárido têm impacto sobre a produção de alimentos em seus territórios rurais, mas também é evidente que isso pode ser contornado quando se tem vontade política.

19 De fato, entre 2011 e 2015, período em que há dados disponíveis para a execução do PAA por município, o Governo Federal dispendeu 1 milhão e 780 mil reais na aquisição de 2 milhões de litros de leite de 374 produtores no Seridó Paraibano, o que representa $87 \%$ dos camponeses envolvidos, $98 \%$ dos produtos adquiridos e $88 \%$ dos recursos aplicados. http://aplicacoes.mds.gov.br/sagi/paa/visi_paa_geral/pg_principal.php?url=abertura, acesso em 24/09/2016. 
BARREIRAS CULTURAIS, BAIXAS CAPACIDADES INSTITUCIONAIS E LIMITES ORGANIZACIONAIS

Segundo os atores territoriais, outras dificuldades se interpõem à boa execução das compras no âmbito do PNAE no Seridó Paraibano. Uma delas é a resistência de alunos, pais de alunos e merendeiras a itens do cardápio regional - por exemplo a aversão ao suco de umbu - mas são as baixas capacidades institucionais das Prefeituras e os limites organizacionais dos camponeses que se destacam como condicionantes importantes para o baixo desempenho observado.

Primeiramente, os gestores ressaltam, invariavelmente, os limites orçamentários das Prefeituras, isto é, a baixa receita própria e a dependência de repasses dos governos estadual e federal, o que dificultaria a aquisição de produtos da Agricultura Familiar por estes apresentarem preços mais elevados. Os prefeitos reclamam, sobretudo, dos valores repassados pelo $\mathrm{PNAE}^{20}$. De fato, o Produto Interno Bruto dos sete municípios do Território totalizou cerca R\$ 340 milhões em 2012, o que representa menos de 1\% do PIB Estadual ${ }^{21}$, mas o preço a ser praticado na compra dos gêneros da Agricultura Familiar deve ser o de mercado, calculado a partir da média do preço dos produtos em três estabelecimentos comerciais do município, necessariamente considerando as feiras livres, como preconiza a regulamentação do FNDE. Assim, os camponeses e suas organizações consideram que este argumento é falacioso e sugerem que os gestores preferem adquirir os produtos de distribuidores, aventando a possibilidade de interesses políticos e econômicos particularistas estarem envolvidos nesse processo.

Há outros problemas ligados à baixa capacidade institucional das Prefeituras que foram citados pelos atores territoriais e verificadas pela pesquisa, quais sejam: (i) a falta de regulamentação dos Sistemas de Inspeção Municipal (SIM) no Território, onde apenas dois municípios - Juazeirinho e Pedra Lavra$\mathrm{da}$ - possuem leis sancionadas neste sentido e a inexistência de estruturas de inspeção sanitária instaladas e em funcionamento, o que impede a aquisição de gêneros de maior valor agregado; (ii) poucas nutricionistas concursadas, sendo a maioria contratada a baixos salários; (iii) despreparo das comissões de licitação municipais, o que redunda em chamadas públicas mal elaboradas e desconectadas da capacidade produtiva local; (iv) carências em relação à assistência técnica; e (v) cobrança de ICMS por falta de providências que garantam a isenção preconizada em Lei.

Por outro lado, no que tange aos problemas organizacionais, foram detectados: (i) funcionamento precário dos Conselhos de Alimentação Escolar, principalmente em decorrência do baixo nível de informações sobre as atribuições do CAE e sua "prefeiturização", isto é, a prevalência de membros ligados às administrações municipais; e (ii) inexistência de cooperativas e baixo profissionalismo das associações, o que impõe à responsabilidade de produtor individual as muitas obrigações burocráticas para a realização das vendas e toda a logística envolvida no processo, o que redunda em dificuldades nas relações contratuais entre os camponeses e o Poder Público.

Finalmente, ainda são ressaltados alguns aspectos da chamada "falta de vontade política" dos gestores, como a realização de licitações ao invés de chamadas públicas, o lançamento de apenas um edital anual, desconsiderando a sazonalidade da produção, sua parca divulgação e, principalmente, o atraso no pagamento das compras realizadas. gramas/alimentacao-escolar/alimentacao-escolar-apresentacao. Acesso em 24/09/2016.

21 http://www.sidra.ibge.gov.br/bda/acervo/acervo9.asp?e=c\&p=IO\&z=t\&o=18. Acesso em 24/09/2016. 


\section{UMA AGENDA}

Diante deste diagnóstico, em 2015 o Fórum Territorial estabeleceu uma agenda para o enfrentamento dos problemas, centrada nas seguintes medidas para superar os problemas: (i) efetivação do Consórcio Público de Inspeção Sanitária com a infraestrutura financiada pelo PROINF (MDA) e o custeio dividido pelas Prefeituras; (ii) melhorias na elaboração e divulgação dos editais de Chamadas Públicas, com no mínimo duas por ano; (iii) colocar a questão da alimentação saudável e da compra de produtos da Agricultura Familiar não apenas na merenda, mas também no currículo; (iv) capacitar os atores envolvidos por meio de um processo de aprendizagem que desenvolva as competências locais; (v) empoderar os membros do Fórum e dos CAEs por meio de formação técnica e política, de maneira a melhorar o controle social; (vi) realização de concursos públicos para a contratação de nutricionistas e melhoria das condições de trabalho destas e das merendeiras; (vii) melhoria da assistência técnica para os camponeses, associações e cooperativas.

\section{A IMPLEMENTAÇÃO DAS SOLUÇÕES}

Esta agenda de intervenções propostas para a solução dos problemas diagnosticados foi pouco efetivada, o que pode ser parcialmente explicado pelo período de turbulência política vivenciado no país e pelo ano eleitoral, fatores que influenciaram a própria dinâmica geral do Fórum Territorial, que sofreu um processo de grande desmobilização nesse período.

Contudo, a formação do Consórcio Público de Serviços de Inspeção Sanitária e SUASA avançou em pelo menos um aspecto: a realização da licitação para a aquisição de veículo utilitário, motocicleta, mobiliário, computador e impressora para sua implantação e estruturação (Convênio MDA/Prefeitura Mu- nicipal de Olivedos $N^{\circ}$ 046079/2014, com recursos do Programa Desenvolvimento Territorial Infraestrutura e Serviços - PROINF), cujos contratos com os vencedores da licitação foram assinados no final de junho de 2016. Entretanto, até o início de novembro do mesmo ano, a Caixa Econômica Federal ainda não havia liberado os recursos para a efetivação da compra, em decorrência da necessidade de ajustamento dos preços, uma vez que o orçamento fora elaborado em meados de 2014.

Quanto às Chamadas Públicas para compras de gêneros da Agricultura Familiar, pouca coisa se alterou, pois todas as prefeituras lançaram apenas um edital no ano de 2016 e ainda com divulgação deficitária, restringindo-se, via de regra, à simples afixação do chamamento público em quadros de avisos nas prefeituras ou secretarias. A exceção foi o município de Juazeirinho, que divulgou seu edital no Portal do Governo do Estado, onde a EMATER/PB oferece uma série de ferramentas e facilidades para os gestores efetivarem as compras ${ }^{22}$. Aliás, é importante ressaltar o empenho da empresa estadual de assistência técnica quanto às compras governamentais da Agricultura Familiar, e, neste sentido, o Portal constitui-se, sem dúvida, num avanço importante para a efetivação dessa política pública. Entretanto, das dez escolas estaduais existentes no Território, apenas cinco divulgaram seus editais no citado Portal, sendo que uma delas, também do município de Juazeirinho, lançou dois editais. Registre-se, porém, que em 2016, além de 599 escolas estaduais (75\%), apenas as secretarias municipais de Educação de João Pessoa e de Juazeirinho, bem como três escolas municipais de Campina Grande serviram-se do Portal para divulgar seus editais, o que, em certa medida, parece confirmar a tese da falta de vontade política dos prefeitos para a aquisição pública de gêneros da Agricultura Familiar para a merenda escolar na Paraíba. 
Não verificamos nenhum avanço em relação aos outros pontos da agenda, a não ser um relativo empoderamento dos atores locais a partir da aprendizagem propiciada pela participação deles nas mesas de diálogo, onde puderam ter acesso a informações importantes. Particularmente no caso dos membros dos CAEs, estes revelavam, via de regra, surpresa quanto a suas atribuições, até então praticamente desconhecidas pela grande maioria. Entretanto, esse empoderamento parece não ter redundado em melhoria no controle social efetivo, uma vez que as medidas pactuadas não progrediram, principalmente pelo fato de os atores locais evitarem se indispor com a gestão municipal, mesmo as entidades representativas dos camponeses, o que evidencia seus limites organizacionais, a outra face explicativa do baixo desempenho das compras governamentais da Agricultura Familiar no Território do Seridó Paraibano.

\section{CONSIDERAÇÕES FINAIS}

Em linhas gerais, pode-se concluir que o baixo desempenho das compras governamentais da Agricultura Familiar para a merenda escolar no Território do Seridó Paraibano tem uma causa fundamental: ela é política, seja no que tange a seus dilemas, seja no que se refere à implementação das soluções construídas coletivamente. Do lado dos gestores, evidencia-se sua falta de vontade e, do lado dos camponeses, sua fraca organização.

Ora, como coroamento do processo de discussão sobre o tema no ano de 2015, promovido pela EMATER/PB e Procuradoria Regional dos Direitos do Cidadão (PRDC) em eventos realizados em todas as regiões $\mathrm{da} \mathrm{Pa}-$ raíba com prefeitos, sociedade civil organizada e órgãos, conselhos e pessoas diretamente envolvidas na execução dos recursos do PNAE, foi realizado um Seminário na Universidade Federal de Campina Grande em que os resultados da pesquisa-ação aqui relatada foram apresentados. Como resultado, em 27 de novembro de 2015 a PRDC enviou notificação aos 223 prefeitos paraibanos, instando-os ao cumprimento o mandado da Lei por meio da adoção de algumas medidas simples construídas nas mesas de diálogo realizadas no Território do Seridó, como a melhoria da redação dos editais, o lançamento de duas Chamadas Públicas por ano e sua ampla divulgação.

Assim, era de se esperar que, pelo menos no Território do Seridó, onde a pesquisa-ação foi realizada e cujo resultado foi o relativo empoderamento dos atores envolvidos no controle social desta política pública, essas medidas de fácil realização fossem adotadas. Mas, nem isso. Ao que tudo indica, os prefeitos fizeram ouvidos de mercador à PRDC e os camponeses e suas organizações não se mobilizaram para que elas fossem cumpridas.

Se o problema é político, sua solução também o é. Daí deixamos uma questão, que será levada aos atores envolvidos na pesquisa -ação em sua última fase, a de avaliação, quando este artigo será apresentado: no quadro de regressão conservadora e neoliberal imposto pelos golpistas da Democracia no Brasil, o que a organização social envolvida com as políticas públicas desenvolvimentistas pode fazer?

Recebido em: 19/07/2016

Aprovado em: 04/11/2016

\section{REFERÊNCIAS}

BELIK, Walter; CUNHA, Altivo R. A. de Almeida. "Abastecimento no Brasil: o desafio de alimentar as cidades e promover o Desenvolvimento Rural". In GRISA, C.; SCHNEIDER, S. (orgs.), Politicas públicas de desenvolvimento rural no Brasil. Porto Alegre, Editora da UFRGS, 2015 (Série Estudos Rurais).

BRASIL. Instituto Brasileiro de Geografia e Estatística. Censo agropecuário 2006. Brasília, IBGE, 2009.

BRASIL. Ministério do Desenvolvimento Agrário. Plano Safra da Agricultura Familiar 2015-2016. Brasília, MDA, 2015.

BRASIL. Ministério do Desenvolvimento Social. Câmara Interministerial de Segurança 
Alimentar e Nutricional. Balanço das Ações do Plano Nacional de Segurança Alimentar e Nutricional - PLANSAN 2012-2015. Brasília, MDS/CAISAN, 2014.

BRASIL. Ministério do Desenvolvimento Social. Câmara Interministerial de Segurança Alimentar e Nutricional (CAISAN). Plano Nacional de Segurança Alimentar e Nutricional - PLANSAN 2016-2019. Brasília, MDS/CAISAN, 2016.

BRASIL. Referências para o desenvolvimento rural sustentável. Brasília, MDA/IICA/CONDRAF/NEAD, 2003.

BRASIL. Territórios da Cidadania: proposta do Ministério do Desenvolvimento Agrário para redução da desigualdade social no meio rural brasileiro. Brasília, MDA, 2008.

CANIELLO, Márcio. "Identidade e qualidade de Vida nos Territórios da Cidadania”. Sociologias, Porto Alegre, Ano 18, $\mathrm{N}^{\circ} 43$, set/dez 2016, p. 300-334.

CANIELLO, Márcio; PIRAUX, Marc; BASTOS, Valério. "Capital social e desempenho institucional no Colegiado Territorial da Borborema, Paraíba”, Revista Raízes, V. 32, No 2, jul/dez 2012, p. 11-31.

CANIELLO, Márcio; PIRAUX, Marc; BASTOS, Valério. "Identidade e Participação Social na gestão do Programa Territórios da Cidadania: um estudo comparativo", Estudos Sociedade e Agricultura, Ano 21, V. 1, 2013, p. 84-107.

CANIELLO, Márcio; PIRAUX, Marc; BASTOS, Valério. "Ideias e práticas na gestão social do Território da Cidadania da Borborema, Paraíba", Sustentabilidade em Debate, V. 4, No 2, 2013b, p. 19-40.

CONCEIÇÃO, Júnia Cristina P. R. da. "Política de comercialização agrícola no Brasil”. In GRISA, C.; SCHNEIDER, S. (orgs.), Politicas públicas de desenvolvimento rural no Brasil. Porto Alegre, Editora da UFRGS, 2015 (Série Estudos Rurais).

DELGADO, Nelson Delgado; LEITE, Sergio Pereira. "O Pronat e o PTC: possibilidades, limites e desafios das políticas territoriais para o desenvolvimento rural". In GRISA, C.; SCHNEIDER, S. (orgs.), Politicas públicas de desenvolvimento rural no Brasil. Porto Alegre,
Editora da UFRGS, 2015 (Série Estudos Rurais).

FAO. Alimentación escolar y las posibilidades de compra directa de la agricultura familiar: Estudio de caso de ocho países. Roma: FAO, 2013.

FAO. Superação da fome e da probreza rural: iniciativas brasileiras. Brasília: FAO, 2016.

FOSTER, George M. "What is a peasant?". In POTTER, J.; DIAZ, M.; FOSTER, G. (orgs.), Peasant society: a reader. Boston, Little Brown, 1967.

FRANÇA, Caio Galvão et al. O censo agropecuário 2006 e a agricultura familiar no Brasil. Brasília: MDA, 2009.

GRISA, Catia; PORTO, Silvio Isopo. “Dez anos de PAA: as contribuições e os desafios para o desenvolvimento rural”. In GRISA, C.; SCHNEIDER, S. (orgs.), Políticas públicas de desenvolvimento rural no Brasil. Porto Alegre, Editora da UFRGS, 2015 (Série Estudos Rurais).

GRISA, Catia; SCHNEIDER, Sérgio. “Três gerações de políticas públicas para a agricultura familiar e formas de interação entre sociedade e Estado no Brasil". In GRISA, C.; SCHNEIDER, S. (orgs.), Políticas públicas de desenvolvimento rural no Brasil. Porto Alegre, Editora da UFRGS, 2015 (Série Estudos Rurais).

KROEBER. Anthopology: race, language, culture, psychologyk, prehistory. New York, Harcourt, Brace, 1948.

NERI, Marcelo Côrtes e SOUZA, Pedro Herculano Cavalcanti Ferreira de. A Década Inclusiva (2001-2011): desigualdade, pobreza e políticas de renda. Comunicados do IPEA, $\mathrm{N}^{\circ}$ 155. Rio de Janeiro, setembro de 2012.

PARAÍBA. Diagnóstico das comunidades do Território do Seridó paraibano. João Pessoa, PROCASE/URGP Seridó, 2014.

PIRAUX, Marc e CANIELLO, Márcio. "Avanços, dilemas e perspectivas da governança territorial no Brasil: reflexões sobre o Programa de Desenvolvimento Sustentável de Territórios Rurais (PRONAT)". Trabalho apresentado no Congreso Internacional Gestión Territorial para el Desarrollo Rural. Construyendo un Paradigma. Bogotá, Colômbia, novembro de 2015. 
PLOEG, Jan Douwe van der. Camponeses e impérios alimentares: lutas por autonomia $e$ sustentabilidade na era da globalização. Porto Alegre, Editora da UFRGS, 2008.

SILVEIRA, Fernando Gaiger; ARRUDA, Pedro; VIEIRA, Izabelle; BATTESTIN, Simone; CAMPOS, Áquila Estevão; SILVA, Wesley. Politicas públicas para o desenvolvimento rural e de combate à pobreza no campo. Brasília, Centro Internacional de Políticas para o Crescimento Inclusivo (IPC-IG), Programa das Nações Unidas para o Desenvolvimento (PNUD), 2016.

SONNINO, Roberta. "Quality food, public procurement, and sustainable development: the school meal revolution in Rome". Environment and Planning A, 41(2), p. 425-440, 2009.

TEIXEIRA, Olívio e CANIELLO, Márcio. "Políticas Públicas, Desenvolvimento Territorial e Suporte à Governança Participativa: o apoio do governo brasileiro para a assessoria dos colegiados de desenvolvimento territorial". Trabalho apresentado no XI Iberian Conference on Rural Studies: Smart and Inclusive Development in Rural Areas. Vila Real, Portugal, outubro de 2016.

THIOLLENT, Michel. Metodologia da Pesquisa-Ação. $2^{\text {a }}$ ed. São Paulo, Cortez; Autores Associados, 1986.

TRICHES, Rozane Márcia. "Repensando o mercado da alimentação escolar: novas institucionalidades para o desenvolvimento rural". In GRISA, C.; SCHNEIDER, S. (orgs.), Politicas públicas de desenvolvimento rural no Brasil. Porto Alegre, Editora da UFRGS, 2015 (Série Estudos Rurais).

TRIPP, David. "Pesquisa-ação: uma introdução metodológica". Educação e Pesquisa, São Paulo, v. 31, n. 3, p. 443-466, set./dez. 2005

UNSCN. The nutrition sensitivity of agriculture and food policies. A synthesis of eight country case studies. Genebra, Suíça, United Nations System Standing Committee on $\mathrm{Nu}-$ trition, 2014.

WOLF, Eric R. Sociedades camponesas. Tradução de Oswaldo Caldeira C. da Silva. Rio de Janeiro, Zahar Editores, 1970.

WOORTMAN, Klaas: “Com parente não se neguceia': o campesinato como ordem mo- ral", in Anuário Antropológico 87. Rio de Janeiro, Tempo Brasileiro; Brasília, Editora da UnB, 1990, pp. 11-73. 